\title{
Handwashing Practices Among Children in Public Schools in Imo State, Nigeria
}

\author{
Chinyere Augusta Nwajiuba ${ }^{1}$, Chinwe Victoria Ogunji ${ }^{1}$, \\ Rowland Chukwuemeka Uwakwe ${ }^{1} \&$ Esther Ihuoma David ${ }^{2}$ \\ ${ }^{1}$ Department of Educational Foundation, Alex-Ekwueme Federal University NdufuAlikelkwo, Ebonyi State, \\ Nigeria \\ ${ }^{2}$ Department of Home Economics Education, Ebonyi State University, Ebonyi State, Nigeria \\ Correspondence: Chinwe Victoria Ogunji, Department of Educational Foundation, Alex-Ekwueme Federal \\ University Ndufu Alike Ikwo, Ebonyi State, Nigeria. E-mail: nickchidi2005@yahoo.com, \\ chinwe.ogunji@funai.edu.ng
}

Received: September 11, 2019 Accepted: October 23, 2019 Online Published: October 31, 2019

doi:10.5539/gjhs.v11n14p15 URL: https://doi.org/10.5539/gjhs.v11n14p15

\begin{abstract}
This study examined the availability and utilization of handwashing facilities among public primary school pupils in Okigwe Education Zone two (2) of Imo State, Nigeria. The study adopted a survey research design. Random sampling technique was used to select a sample size for the study. 295 pupils (age bracket 6-14 years) from 12 public primary schools and their form teachers participated in the study. Data were collected with the aid of a structured questionnaire designed from UNICEF's checklist modules for appraising hand washing facilities in schools. Also, observation and focus group discussion were used for the data collection on handwashing practices among pupils using hand washing facilities.Data generated were analyzed using percentage and frequency distribution counts in order to answer the research questions. All information from the focus group discussion using codes and themes were transcribed, grouped and analyzed based on the specific objectives. Findings suggest that out of the twelve schools observed, only two schools had both a handwashing basin with clean water that runs and improvised handwashing facilities at the same time. Based on the findings, hand washing facilities and supplies should be a major priority in all primary schools in Okigwe Education Zone 2 because of its importance in preventing communicable diseases. School health educators should work in conjunction with the Parents Teachers Association of each school to ensure constant and adequate provision of handwashing facilities and supplies. This will further encourage their usage and also reduce absence from schools due to infections.
\end{abstract}

Keywords: hand washing, children, public schools, facilities

\section{Introduction}

The availability and utilization of handwashing facilities in primary schools have become a public discourse among school health educators and advocates of primary education. Handwashing is referred to as the act of removing dirt from the hands by cleaning the hands (Dajaan, Addo, Ojo, Amegah, Loveland, Bechala, \& Benjamin, 2018). It has been admitted as one of the good practices of preventing communicable diseases contacted by unwashed hands in developing countries. It is seen as convenient, effective and cost-effective especially for children susceptible to infections passed on through hands (Burns, Maughan-Brown, \& Mouzinho, 2018). Most infectious diseases such as diarrhoeal, acute respiratory infection are contacted and transmitted by unwashed and contaminated hands (Oduntan, 2010). The World Health Organisation (WHO) reports that diarrhoea is the second leading cause of death in children under five years of age, accounting for 1.7 billion cases, and the death of 525,000 children annually (WHO, 2017). In Nigeria, over 150,000 deaths occur annually amongst children due to diarrhoea. Good handwashing practice is, therefore, a prerequisite to a child's survival (UNICEF, 2008; Haruna, Kabir, \& Sambo, 2016).

Critical times for handwashing include after using the toilet, after cleaning a child, and before handling food (Global Hand Washing Day guide (GHWD), 2017). For children, in particular, critical moments include after playing outside, or with toys and pets (Quinn, 2019; Ali, 2008). World Health Organization (2009) opines that the proper handwashing practices include rubbing the two hands with soap for at least 20 seconds and then rinse thoroughly under running water. Allow the hands to dry properly afterwards. Handwashing facilities include soap, 
ash, water, disinfectants, towels, handwashing point, tippy taps and bowls (Dajaan et al., 2018). Studies (e.g. Lopez- Quintero et al., 2009; Pati et al., 2014) revealed that unavailability of soap and clean towel is a negative factor affecting compliance. According to a UNICEF report, involving children themselves as active participants in promoting handwashing with soap in schools creates in the children a sense of ownership that makes new behaviours more likely to be adhered to (UNICEF, 2008). Therefore, key hygiene habits such as good handwashing practices that are likely to be taken further into adulthood can be adopted by encouraging millions of school children to engage in these good repetitive, non-reflective behaviours. Bandura's modelling theory (1977) is used to explain the relevance of handwashing practices among children in this study because it is a strong indicator that young children have the potential to learn new behaviours, such as hand washing, simply by watching other adults and children wash their hands.

These habits can also contribute to the achievement of two of the Sustainable Development Goals which support Education and Health (United Nations General Assembly, 2015). Bennell (2002) argues that since school children in developing countries account for up to half of the population, promotion of good hygiene and handwashing practice is not only necessary but also very relevant. This is the reason why UNICEF drew the attention of Nigerians to the life-saving importance of handwashing with soap, clean ash and water and that diarrhoea is both preventable and treatable, and that there was no need for developing countries to continue to pay the price of this disease in lost lives, missed school days, reduced resistance to infections, impaired growth, malnutrition and poverty (UNICEF, 2010). Burns et al. (2018) also asserted that children who practised hand washing had better health outcomes and reduced child mortality rate.

A review of primary school hygiene facilities in a developed country, suggests that the physical quality of any toilet and handwashing facility is an important determinant of whether and how it is used especially for school children (Reeve \& Poore, 2012; Dajaan, 2018). Hart and Roger (1997) identified lack of time, poor adult modelling of regular hand washing and unattractive facilities as important barriers to regular handwashing in schools. In the same vein, an online survey of 512 children showed that nearly half of them agreed that time constraints, supply shortages and untidy restrooms are among the top reasons why students say they do not wash their hands often during the school day (American Society of Microbiology, 2005). Currently, Nigeria is one of the countries whose sanitation coverage rates are between $20 \%$ and $40 \%$ points below the MDG targets (Aremu, 2012). Most public primary and secondary schools in Nigeria are short of the basic water and sanitation facilities (Aremu, 2012). This has resulted in a high prevalence rate of water- and sanitation-related diseases causing many children to fall ill and stay away from school or even die (UNICEF, 2008).

Children tend to be absent from school, frequently get sick and perform poorly when suffering from diseases related to poor hand washing. The diseases are transmitted during a close relationship or interaction in school. It is believed that diseases are easily spread when the children are in school compared to any other place in the society. Diarrhoeal diseases, according to WHO (2017), are preventable by simple hand washing with soap and can significantly reduce deaths due to these diseases by half. There is, therefore, a need to examine the extent of availability of handwashing facilities and their utilization among primary schools' pupils in Okigwe Education zone 2 in Imo State. Exploring the availability and practice of handwashing among children reinforces the need and importance of the good practice of handwashing. It is in light of this, that this study is set to investigate the availability and utilization of handwashing facilities in primary schools in Okigwe Education zone 2 in Imo State, Nigeria.

\subsection{Purpose of the Study}

The main purpose of this study was to investigate the extent of availability and utilization of handwashing facilities among public primary school pupils in Okigwe Education zone 2. The study will specifically;

1). Identify available handwashing facilities (clean water, soap, single-use towel) in primary schools in Okigwe Education zone 2.

2). Examine handwashing practices among pupils in public primary schools in Okigwe Education zone 2.

\subsection{Research Questions}

The following research questions were posed to guide the study:

1). What are the available facilities for handwashing in the public primary schools in Okigwe Education zone 2?

2). What handwashing practices do pupils exhibit in the primary schools in Okigwe Education zone 2? 


\section{Methodology}

\subsection{Ethical Approval}

Ethical considerations involved written permission which was sought and obtained from the school authorities. The objectives of the study, its methods and its significance were explained to the authorities and the participating teachers and pupils. Only those who gave informed consent were recruited for the study. Research ethics approval was also sought and approval received from the university management. In addition to this, principles expressed in the Helsinki declaration of 1964 were observed and complied within the course of this study.

\subsection{Design and Area of Study}

A survey research design was adopted for the study. This study was carried out in primary schools in Okigwe Education zone 2 which is one of three educational zones in Imo State. The population for this study comprised of primary one to six (1-6) pupils of ages 6 to 14 years and teachers in the zone. The population of public primary school pupils in Okigwe Education Zone 2 is 21,996 and that of the teachers is 1,203 (State Universal Basic Education Board, Owerri, 2014). Using a random sampling technique, two public primary schools were chosen from each of the six Local Government Areas in Okigwe zone. The list of the public schools served as the sample frame. Twelve public primary schools in all were randomly selected by balloting. Pupils selected were from basic classes 1 to 6 . A total of 295 pupils were selected randomly via a "yes" or "no" ballot. Teachers were randomly selected for a focus group discussion. A total of 12 form teachers of the pupils participated in the focus group discussion.

\subsection{Data Collection}

The Data were collected with the aid of a self-structured questionnaire designed from UNICEF's checklist modules used for assessing handwashing facilities in schools. Also, observation and focus group discussion were used to collect data on the practices of handwashing among pupils using prescribed hand washing facilities. Primary school pupils between the ages of 6-14 years old were considered appropriate for the instrument. A questionnaire named "Availability and Utilization of Handwashing Facilities in Public Primary schools" (AUHF) was used. The first section elicited information about the school and demographic characteristics. Using the checklist, facilities available (clean water, soap and hand towel (disposable) were noted. Pearson product-moment correlation coefficient was used to establish the reliability of the instrument which involved test-retest. A coefficient $r$ of 0.73 was obtained. The instrument was administered using a face-to-face method. This was done with the help of four trained research assistants. The researchers explained the various sections of the questionnaire to the respondents who were asked not to leave any of the items unanswered. Also, observation and focus group discussion guide were utilized to obtain additional information on handwashing practices among pupils using hand washing facilities.

\subsection{Data Analysis}

Data generated were analyzed using percentage and frequency distribution counts in order to answer the research questions. All information from the focus group discussion using codes and themes were transcribed, grouped and analyzed based on the specific objectives.

\section{Results}

\subsection{Background Characteristics}

A total of 295 pupils, $51.5 \%$ of females participated in the study. Over $80 \%$ of pupils were 11 years or younger (Table 1).

Table 1. Background characteristics of respondents (pupils) $(n=295)$

\begin{tabular}{ll}
\hline Factor & Count \\
\hline Sex & \\
Female & $152(51.5)$ \\
Male & $143(48.5)$ \\
\hline Age range (years) & \\
$6-8$ & $103(34.9)$ \\
$9-11$ & $143(48.9)$ \\
$12-14$ & $49(16.7)$ \\
\hline
\end{tabular}




\subsection{Research Question I}

What are the available handwashing facilities in public primary schools in Okigwe education zone 2?

Table 2. Distribution of handwashing facilities in schools

\begin{tabular}{lc}
\hline Handwashing Facilities & Number Present in schools \\
\hline Availability of one or more sinks with running water & 2 \\
Availability of one or more receptors used for communal hand washing & 7 \\
Availability of one or more plastic containers with tap running water & 2 \\
Presence of soap in all facilities & 0 \\
Presence of soap in some facilities & 1 \\
Availability of towels in all facilities & 0 \\
Availability of towels in some facilities & 0 \\
\hline
\end{tabular}

The study took a record of these facilities using the checklist, in 12 schools. Table 2 showcased the availability of such facilities in schools. Out of the twelve schools observed, only two schools had both a functional handwashing sink with clean running water and improvised handwashing facilities at the same time. Some other schools had sinks, which were faulty with leaking pipes. Seven out of the 12 schools used makeshift receptors for communal handwashing. Two schools had plastic containers with a tap for clean running water made available to the school children for rinsing their hands. In one school, soap was made available for the children. While in all the schools, there were no towels for wiping hands after wash.

Also, focus group discussion with the children disclosed that the school where soap was available, permission from the teachers were sought before usage. This is because the soap is kept in a cupboard and not close to the handwashing facilities thereby hindering the children from regularly using the soap in hand washing. The children also acknowledged the fact that they were often in a hurry to play or eat, before the break period was over, hence their negligence of washing their hands.

\subsection{Research Question 2}

What handwashing practices do pupils exhibit in the primary schools in Okigwe Education zone 2?

Table 3. Distribution of handwashing practice with soap

\begin{tabular}{llc}
\hline Observed practices & Observed (n) & Washing appropriately (\%) \\
\hline Handwashing with soap after toilet use & $46(15.6 \%)$ & 0 \\
Handwashing with soap before eating & $91(30.9 \%)$ & 0 \\
Handwashing with soap after eating & $83(28.1 \%)$ & 0 \\
Handwashing with soap after playing & $43(14.5 \%)$ & 0 \\
Handwashing with soap after picking & $32(10.8 \%)$ & 0 \\
papers from school premises & & 0 \\
\hline
\end{tabular}

Results in Table 3 reveal that $30.9 \%$ of the pupils studied wash their hands with soap before eating, $28.1 \%$ wash their hands with soap after eating, $15.6 \%$ of the pupils wash their hands with soap after using the toilet, $14.5 \%$ wash their hands with soap after playing and $10.8 \%$ wash their hands with soap after picking papers from the compound. However, results suggest that none of these children washed their hands appropriately according to the standard for washing hands, which requires the rubbing of two hands for roughly 20 seconds under running water with neutral soap.

The focus group discussions with the school children revealed that the children knew that handwashing is a fundamental pillar in disease prevention. The following quotes are the viewpoints of some of the school children about what is likely to happen when their hands are not washed: 


\section{"You can get germs and die if you don't wash your hand after using the toilet." \\ "Your hand will smell and if you eat with it your stomach will hurt you and you will fall sick."}

They further said that the critical moments for washing hands were before and after eating, after toilet use, after playing and immediately after contact with body fluids such as coughing or sneezing.

Expressions from focus group discussions with both teachers and children showed that even though teachers could properly demonstrate hand washing technique with soap, most of the children could not do so, although they mentioned the use of soap.

\section{Discussion of Findings}

Translating handwashing practices and knowledge obtained by pupils requires the presence of some hand washing amenities in both schools and homes of the pupils. Contrary to this, findings of this study indicated that handwashing facilities such as clean running water, soap etc were deficient in a greater number of the schools. UNICEF (2018) has advocated excellent handwashing observation as a requirement for the survival of a child. The practice of handwashing among children can be positively influenced by sufficient accessibility of handwashing facilities (Aremu, 2012). Insufficient hand washing facilities as found in the study areas is in tandem with the report of Steiner-Asiedu et al. (2011) who discovered the lack of handwashing facilities such as, towel, soap and clean running water in a good number of schools. As described by Dajaan et al. (2018), handwashing facilities should include soap, towels, ash, water, disinfectant, handwashing point, tippy taps and bowls. Several reports from emerging countries consistently show that soap and water are often unavailable in schools (Lopez-Quintero et al., 2009). Huge plastic buckets and poly-tanks are fitting tools needed to promote handwashingbehaviour. This is because proper handwashing requires the use of soap and clean running water from a tap or an improvised tap. Indeed, the frequently make-do hand washing amenities in the studied schools were plastic buckets. However, in all the schools, there were no towels for wiping hands after washing and only one school had soap. Hand washing without soap is a major barrier to proper washing of hands. The practice is below the UNESCO (1999) standard which specifies that the lowest quantity of a single set of functional handwashing facility should be available in each school. Moreso, focus group discussion also affirms that there is improper hand washing because soap is not always available for use. This aligns with the study of Pati et al. (2014) in India who stated that over $85 \%$ of the children affirmed unavailability of soap to wash hands in schools.

Handwashing awareness and understanding does not constantly transform into practice (Ebong, 1994; Burns et al., 2018). The current study suggests that these children are aware of handwashing but did not demonstrate proper handwashing practice. The reason could partly be as a result of the unavailability of handwashing amenities in the studied schools. Also, teachers are not being encouraged to teach children proper hand washing techniques (WHO, 2009; CDC, 2016). The practical rates of handwashing with soap at vital moments range from zero to $34 \%$ (GHWD, 2017) as indicated by some other observational studies. Handwashing is an effective and affordable means of stopping the increase of infections along with germs as affirmed by the children in the study area. This also agrees with the assertions of (CDC, 2016; Haruna et al., 2016). The implications of all observed trends together with the recent study is that more work needs to be done. This is in terms of providing handwashingfacilities both at home and schools to promote good handwashing behaviours among children. On the other hand, lack of facilities becomes a hindrance to the proper practice of handwashing even when children may have knowledge of the right practices. Propagation of information to children in the schools is the expected duty of a trained teacher. The children, in turn, will pass on the information to peers, siblings, parents and other out-of-school children as change agents.

Though handwashing is not absolutely taught as a subject, yet it is part of Environmental and Religious Studies, Basic Science and Moral education subjects taught at the primary levels of the Nigeria Educational System. This defeats the whole aim of using school children as change agents for handwashing practices. School hygiene programmes have existed for a long time while hygiene and sanitation messages are often included in the formal curriculum. It is important to note that when to wash hands and how it is done are critical determinants in maintaining good personal hygiene and sanitation.

\section{Conclusion}

The pupils had good knowledge of handwashing practice, but the inadequate provision of handwashing facilities at school did not allow them to practice the handwashing knowledge already acquired. Also, the pupils did not demonstrate proper hand washing techniques. Hand washing practices in public schools were poorly done. Moreover, utilization of handwashing facilities is hindered by the inadequate provision, and lack of maintenance culture of available facilities. Teachers need resources and training in proper handwashing to teach and supervise 
children if they should be agents of change.

\subsection{Limitations}

In the course of the study, the following limitations were experienced; bad road which affected the cost of accessing the schools used for the study. This also prolonged the data collection which spilled into more days than planned. Data was collected at the onset of the planting season. This factor kept some pupils away from school as they were involved in farming activities with their parents though with the intention of coming back to school after the season was over.

\subsection{Recommendations}

Based on the findings of this study, the following recommendations are made;

1). Handwashing facilities and supplies should be a major priority in all primary schools in Okigwe education zone 2 because of its importance in preventing communicable diseases. All stakeholders should work in conjunction with the Parents Teachers Association of each school to ensure constant and adequate provision. This will further encourage usage and consequently reduce the loss of valuable school days.

2). Emphasis should be laid on proper handwashing practice by the government to promote healthy school days.

3). Teachers should be encouraged to teach pupils how to practice handwashing. Adequate handwashing facilities should be provided to help eliminate any hindrance to handwashing practice by children.

4). Handwashing campaigns should be carried out and they can be made more effective when the children are targeted directly to achieve behavioural change.

\subsection{Suggestions for Further Studies}

1) Factors militating against the effective implementation of hand washing practices in public schools.

2) Accessing the availability of handwashing facilities in public schools.

\section{Competing Interests Statement}

The authors declare that there are no competing or potential conflicts of interest.

\section{References}

Ali, S. H. (2008). Children mark global handwashing day in remote Pakistan village world vision, Pakistan. Retrieved November 19, 2011, from http://meero.worldvision.org/news_article.Php?news ID= 16938 $\&$ CountryID $=18$.

American Society for Microbiology. (2005).Women better at hand hygiene habits, hands down. Science daily. Retrieved June 11th, 2019, from https://www.sciencedaily .com/release/2005/01/050922020856.htm

Aremu A. S. (2012). Assessment of Sanitation Facilities in Primary Schools within Ilorin, Nigeria. Journal of Applied Sciences in Environmental Sanitation, 7(1), 29-33.

Bandura, A. (1977) Social Learning Theory. New York: General Learning Press. Retrieved July 20th, 2019, from https://www.instructionaldesign.org

Bennell, P. (2002). Hitting the targetdoubling primary school enrolments in sub-Saharan Africa by 2015.World Development, 30(7), 1179-1194.https://doi.org/10.1016/S0305-750X(02)00027-X

Bolt, E., Shordt, K., \& Krukkert, I. (2006).School sanitation and hygiene education results from the assessment of a 6-country pilot project delft. Retrieved July 30th, 2011, from International Water and Sanitation Centre, Netherlands.http://www.irc.nl/page/29459.

Burns, J., Maughan-Brown, B., \& Mouzinho, A. (2018).Washing with Hope: Evidence of improved handwashing among children in South Africa from a pilot study of novel soap technology. BMC Public Health, 18, 709. https://doi.org/10.1186/s12889-018-5573-8

CDC. (2016). Handwashing: Clean Hands save lives. Retrieved 6th August, 2019, from https://www.cdc.gov.

Center for Disease Control and Prevention. (2007). Hand washing recommendation to reduce disease transmission from animals in public setting. Appendix C,56(RR05), 16-17. Retrieved from mmwrq@cdc.gov

Curtis, V., \& Cairncross, S. (2003). Effect of washing hands with soap on diarrhea risk in the community.A systematic review. Retrieved January 4th, 2009, from https://www.ncbi.nlm.nih.gov/pubmedhealth/PMH0020377/

Dajaan, D. S., Addo, H. O., Ojoh Amegah, K. E., Loveland, F., Bachala, B. D., \& Benjamin, B. B. (2018). Hand 
washing, knowledge and practices among public primary schools in the Kintampo municipality of Ghana. International Journal of Community Med. Public Health, 5, 2205-2216. https://doi.org/10.18203/2394-6040.ijcmph20182146

Ebong R., D. (1994). Environmental health knowledge and practice survey among secondary school children in Zaria, Nigeria. Retrieved June 20th, 2019, from https://www.ncbi.nim.gov/m/pubmed $/ 803387$

Global hand washing day. (2017). Our hands our future. USAID. Retrieved July 25th, 2019, from https://www.globalwaters.org/events/global-handwashing-day

Haruna, S. W., Gobir, A. A., \& Sambo, M. N. (2016). Knowledge, attitude and practice of handwashing with soap in rural community in North-Western Nigeria. Savannah Journal of Medical Research and Practice: Advanced Research, 5(2). Health Organisation, 2003, WHO/SDE/WSH/03.02. https://doi.org/10.4314/sjmrp.v5i2.4

Imo State University Basic Education Board. (2014). School Enrolments 2014.

Lopez-Quintero, C., Freeman, P., \& Neumark, Y. (2009). Hand washing among school children in Bogata, Colombia. American Journal of Public Health, 99(1), 94-101. https://doi.org/10.2105/AJPH.2007.129759

Oduntan, S. O. (2010). The health of Nigerian children school age (5-16years) III. The environmental determinants of the health of the children: General discussion and recommendation. Annals of tropical medicine and parasitology, 68, 157-165. https://doi.org/10.1080/00034983.1974.11686933

Pati, S. S., Kadam, A. S., \& Chauhan, S. (2014). Hand hygiene behaviour among urban slum children and their caretakers in Odisha, India. Journal of Prev and Hygiene, 55, 65-68.

Quinn, P. (2019). Illinois Early Learning Project. Retrieved July 27th, 2019, from http://illinoisearlylearning.org/tipsheets/ handwashing.htm

Reeve, A., \& Poore, G. (2012). Domestic quantity, service level and health. Geneva: World Health Organization.

Roger., A. H. (1997). Children participation.The theory and practice of involving young citizen in community development and environmental care. New York. Taylor and Francis publishers.

Steiner-Asiedu, M., Van-Ess, S. E., Papoe, M., Setorglo, J., Asiedu, D. K., \& Anderson, A. K. (2011).Hand Washing Practices among School Children in Ghana. Current Research Journal of Social Sciences, 3(4), 293-300.

United Nations Children's Emergency Fund. (2008). Information sheet on water, sanitation and hygiene in Nigeria. Retrieved January 17, 2019, from www.unicef.org/wcaro/wcaro-factsheets

United Nations Children's Fund. (1998). A Manual on School Sanitation and Hygiene.Water, Environment and Sanitation Technical Guidelines Series No. 5. New York, NY. Retrieved July 15, 2019, from https://www.unicef.org/wash/files/Sch_e.pdf

UNESCO. (1999). Guidelines for the provision of safer water sanitation facilities in schools(1st ed.). School feeding program. Retrieved July 10, 2019, from htt://www.unesco.org/education/fresh

United Nations General Assembly. (2015). Sustainable development goals. Retrieved 6th August, 2019, from https://www.un.org.envision 2030

United States Agency for International Development (USAID). (1990). Strategies for drinking water and sanitation programmes for Child Survival (pp. 1-62). Washington, D.C.

World Health Organization [WHO]. (2018). Global handwashing day.Planner's guide (pp. 16-20). Retrieved June 15th, 2019, from http://globalhandwashing.org $>$ resources/global-handwashing-day-planners-guide-2018

World Health Organization [WHO]. (2009).Hand Hygiene-World Health Organization Why, How and When World Alliance for safer health care. World Health Organization.

World Health Organization [WHO]. (2017). Diarrhoeal disease factsheet. WHO, Geneva. Retrieved August 11th, 2018, from http://www.who.int/news-room/fact-sheets/detail/diarrhoeal-disease

World Health Organization [WHO]. (2004). Clean Home. A guide for Caregivers. Retrieved May 5th, 2012, from www.whocaregivers.guide

World Health Organization [WHO]. (2004). First adapt then act! A booklet to promote safer food in diverse settings.SEA-EH-546. WHO Regional Office for South-East Asia, New Delhi. Retrieved March 3rd, 2012, from http://www.who.int/foodsafety/consumer/5keys/en 
World Health Organization [WHO]. (2007). The physical school environment: An essential component of a health-promoting school. Information Series on School Health, WHO, Geneva. Retrieved July 5th, 2019, from http://citeseerx.ist.psu.edu/viewdoc/download?doi=10.1.1.378.4292\&rep=rep1\&type=pdf

World News. (2009). Hand Washing Marks Opening of Schools Today. Retrieved July 23, 2009, from http://www.com/.../Hand.washing_marks_opening_of_school_today

\section{Copyrights}

Copyright for this article is retained by the author(s), with first publication rights granted to the journal.

This is an open-access article distributed under the terms and conditions of the Creative Commons Attribution license (http://creativecommons.org/licenses/by/4.0/). 